\title{
Novel prospects for evaluation of follicle wall blood flow using color-Doppler ultrasonography
}

\author{
S.G.S. de Tarso, G.M. Ishak, G.D.A. Gastal, S.T. Bashir, M.O. Gastal, E.L. Gastal ${ }^{1}$
}

Department of Animal Science, Food and Nutrition, Southern Illinois University, Carbondale, IL, 62901, USA.

\begin{abstract}
The goal of this study was to develop an objective method for evaluation of ovarian follicle wall blood flow in cattle. Two subjective methods were used: (I) real-time ultrasound evaluations performed by one operator in the barn and (II) video clip evaluations performed by four operators in the laboratory. The following objective methods evaluated in the laboratory were used for comparison: (I) percentage of follicle wall circumference under blood flow (WUF) and (II) pixel area of color-Doppler signals. Cows $(n=21)$ were submitted to a synchronization protocol, follicles $\geq 7 \mathrm{~mm}$ were measured, and blood flow was evaluated every $12 \mathrm{~h}$ until ovulation using color-Doppler ultrasonography. No difference $(\mathrm{P}>0.05)$ was observed among laboratory operators from day 2 of training onwards. Therefore, an average score of all operators was used for comparisons among different methods. Both subjective and objective methods of evaluation showed an increase $(\mathrm{P}<0.0001)$ in follicle blood flow over time. Higher $(\mathrm{P}<0.001)$ correlations were obtained between WUF and subjective laboratory evaluation than between WUF and pixel area or WUF and subjective barn data. Higher $(\mathrm{P}<0.0003)$ correlation coefficients were observed for WUF than for the pixel area when compared with the barn $(r=0.70 v s . r=0.42)$ or laboratory $(r=0.84$ vs. $r=0.62)$ data. Subjective evaluations at the laboratory and barn produced stronger correlations with WUF $(\mathrm{P}<0.0008)$ than with pixel area $(\mathrm{P}<0.01)$. In conclusion, WUF is an effective and reliable method for objective evaluation of follicle wall blood flow in cows.
\end{abstract}

Keywords: follicle, blood flow, color-Doppler, cows, ultrasonography.

\section{Introduction}

Since the development of ultrasound machines with color-Doppler mode for use in human and veterinary medicine, several studies have been produced to elucidate the interactions between blood flow and function of organs (Blasco et al., 1975; Brannstorm et al., 1998; Bollwein et al., 2000; Acosta and Miyamoto, 2004; Acosta, 2007; Herzog and Bollwein, 2007; Adams et al., 2008; Viana et al., 2013). In reproduction, vascular events in the preovulatory follicle (POF) and subsequent corpus luteum (CL) formation are crucial for proper functioning of reproductive events (Bollwein et al., 2002; Acosta et al., 2003; Acosta and Miyamoto,
2004; de Tarso et al., 2015). Follicle blood flow has been shown to be predictive of the following: subsequent CL blood flow and plasma progesterone concentrations (de Tarso et al., 2015), developmental and ovulatory status of follicles (Brannstorm et al., 1998; Acosta and Miyamoto, 2004; Gastal et al., 2006; Acosta, 2007; Siddiqui et al., 2010; Gastal and Gastal, 2011), establishment of pregnancy and/or fertility (Dickey, 1997; Silva et al., 2006; Siddiqui et al., 2009a), and maturity of oocytes and success of in vitro fertilization and embryo development (Bhal et al., 1999; Coulam et al., 1999; Huey et al., 1999; Ginther et al., 2007b; Siddiqui et al., 2009b) in several species such as cattle, horses, and women.

To successfully correlate the vascular profile in preovulatory and luteal phases with the subsequent outcome in fertility, methods of evaluating blood flow should reliably translate the physiological events (Fein et al., 1995; York and Kim, 1999). Currently, there are two methodologies to evaluate and score color-flow images in ultrasonographic examinations. The first methodology involves the objective evaluation of the vascular perfusion of a structure (i.e., follicle, CL). Three images with maximum blood flow are selected using a video-editing program, and pixel aggregates are selected, extracted, saved, and processed using a specific software to generate the area of the colored pixels and the pixel number (Miyazaki et al., 1998; Acosta et al., 2002, 2003; Ginther, 2007; Ginther et al., 2007a; Araujo and Ginther, 2009). This method of evaluation has been used as a gold standard test to compare results with subjective methods (Ginther and Utt, 2004; Ginther et al., 2007a). The second methodology involves the subjective evaluation (percentage or score system) of the vascular perfusion of a structure, based on the estimated proportion of the structure with color signals, according to the sonographer's judgment (Bhal et al., 1999; Gastal et al., 2006; Ginther, 2007).

Evaluation of blood flow in follicles and CLs through color-Doppler ultrasonography can be quickly performed subjectively in the field (Ginther, 2007; Herzog and Bollwein, 2007; Miyamoto et al., 2009; Bollwein et al., 2012; Viana et al., 2013) and has important clinical and research applications (Bollwein et al., 2000, 2012; Ginther, 2007; Adams et al., 2008; Miyamoto et al., 2009). Although the subjective evaluation of follicle blood flow has been used in clinical and research settings in humans and farm species for more than two decades (Bourne et al., 1991; Miyazaki et al., 1998; Coulam et al., 1999; Shrestha et al., 2006; 
Silva et al., 2006; Siddiqui et al., 2009a, b), a validation of a methodology for evaluation of follicle blood flow, using subjective and objective approaches, has not been reported yet. Therefore, a validation and comparison between methodologies is needed.

To reliably evaluate follicle blood flow and compare with results obtained by real-time scans, an objective method for analyzing the percentage of follicle wall circumference under blood flow (WUF) was developed in this study. This method follows a similar approach of follicle blood flow evaluations made subjectively in the field or in a doctor's office, allowing generation of information of the overall structure, rather than only from images with maximum blood flow.

The objectives of this study were: (1) to validate a new objective method (WUF) for evaluation of follicular wall blood flow; (2) to compare the WUF, area of colored pixels in the follicle wall, and subjective (barn vs. laboratory) evaluation methodologies; and (3) to compare the results of four trained operators using the subjective method to evaluate follicle wall blood flow and to correlate this with the WUF and pixel area objective methods.

The hypotheses tested in the current study were as follows: (I) the objective pixel area method for evaluation of blood flow perfusion in follicles does not assure to be a gold standard method to validate results obtained by the subjective blood flow percentage method in real-time scans; (II) the WUF is an accurate and reliable method for evaluation of follicle wall blood flow compared to the pixel area method; and (III) welltrained operators produce highly correlated results of follicle blood flow with the WUF method.

\section{Materials and Methods}

\section{Animals}

Procedures were approved and conducted in accordance with the United States Government Principals for the Utilization and Care of Vertebrate Animals Used in Testing, Research and Training. The research protocol (\#12-045) was approved by the Institutional Animal Care and Use Committee of Southern Illinois University. Aberdeen Angus beef cows (Bos taurus; $\mathrm{n}=21$ ) from the Beef Center of the College of Agricultural Science, Southern Illinois University were used. Cows were housed in free stalls, had unrestricted access to water, and were fed with hay and rations twice daily. Animals were $3.0 \pm 0.2$ years old and the body condition score was 5.0 (score range, 1 = thin, 9 = obese; Eversole et al., 2009).

\section{Study design}

All cows were submitted to a 7-day Co-Synch + CIDR protocol. Briefly, on day 0 of the protocol, animals were injected intramuscularly $(86 \mu \mathrm{g} / \mathrm{cow})$ with a gonadotropin-releasing hormone $(\mathrm{GnRH})$ analogue (gonadorelin diacetate tetrahydrate, Fertagyl®; Intervet, Unterschleissheim, Germany). On the same day, an intravaginal progesterone-releasing device (Eazi-
Breed $^{\mathrm{TM}}$ CIDR $\AA$, Pfizer Animal Health, New York, USA) was inserted in all animals. A prostaglandin F2 $\alpha$ (PGF2 $\alpha$ ) analogue (dinoprost tromethamine, Lutalyse ${ }^{\circledR}$; Pfizer, Animal Health, New York, USA) was administered intramuscularly ( $25 \mathrm{mg} / \mathrm{cow}) 7$ days later, along with the removal of the CIDR. A second dose of GnRH $(86 \mu \mathrm{g} / \mathrm{cow})$ was administered $60 \mathrm{~h}$ (day 10) after CIDR removal. Beginning on day 7 of the protocol, follicles $\geq 7 \mathrm{~mm}$ in diameter were measured (Ginther, 1998), and the percentage of the follicular wall with blood flow signals was assessed every $12 \mathrm{~h}$ for approximately 3.5 days, until ovulation. A total of 434 still images and 311 video clips were recorded. For the subjective evaluation (follicle wall blood flow percentage), two approaches were used: (I) real-time evaluation performed at the farm by one trained operator, and (II) video clip evaluation in the laboratory by four trained operators. For the objective evaluation, images were blindly selected, extracted, and edited in two software programs (Adobe Photoshop CS4 version 11.0, Adobe Systems, San Jose, CA, USA; Image $\mathbf{J}^{\circledR}$ version $1.45 \mathrm{~s}$, National Institutes of Health, Bethesda, MD, USA). Three end points were generated: (1) estimate of the percentage of follicle wall blood flow, (2) area of colored pixels in the follicle wall, and (3) percentage of follicle wall circumference under blood flow (WUF).

\section{Ultrasound exams}

All ultrasonographic exams were performed by a single operator (SGST) using a portable duplex colorDoppler ultrasound machine (Sonoscape S8 Bedford Hill, NY, USA) connected to a linear probe 5.0 - 10.0 $\mathrm{MHz} / 46 \mathrm{~mm}$. For all ultrasound exams, the settings of frequency and patterns of gain and color were kept constant throughout the study. Diameter (average of height and width) was obtained from three still images at the maximum dimension of each follicle within each time point (Ginther, 1998). Three still images and short video clips $(\leq 15 \mathrm{sec})$ with the maximum color-Doppler signals of each follicle (Fig. 1) were recorded using the media function of the equipment for subsequent laboratory analyses.

\section{Operator's training for lab evaluation}

Four operators were trained to estimate the follicle wall blood flow percentage, following the procedures described in the subsequent sections. The operators had different levels of previous knowledge regarding the evaluation of follicle wall blood flow using color-Doppler ultrasonography. Training cards with a representative blood flow scale $(0-100 \%)$ were used by each operator for two days to elucidate examples of blood flow dispersion on the follicular wall. In addition, operator's training was performed in sessions in the laboratory with a high resolution TV screen (55" monitor; Class 55LF6090, LG Electronics, USA), with the trainee analyzing 40 video clips per each session. Sessions were held not longer than $48 \mathrm{~h}$ apart. At the beginning of each session, operators analyzed and discussed the data collected during the previous 
session in order to improve accordance of the results. When the correlation coefficients between all pairs of operators were $>0.85$ for six consecutive training sessions, the operators were considered to be trained.

\section{Cow 1}

\section{Pixel area}

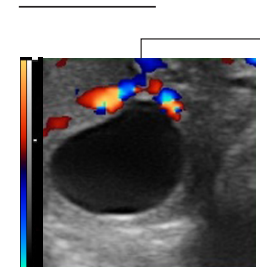

Still images

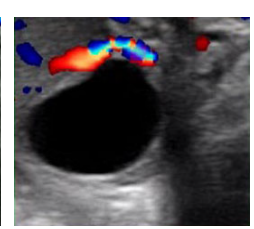

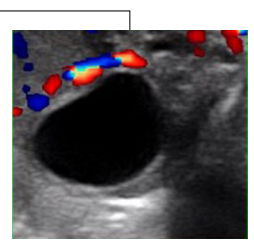

Still images
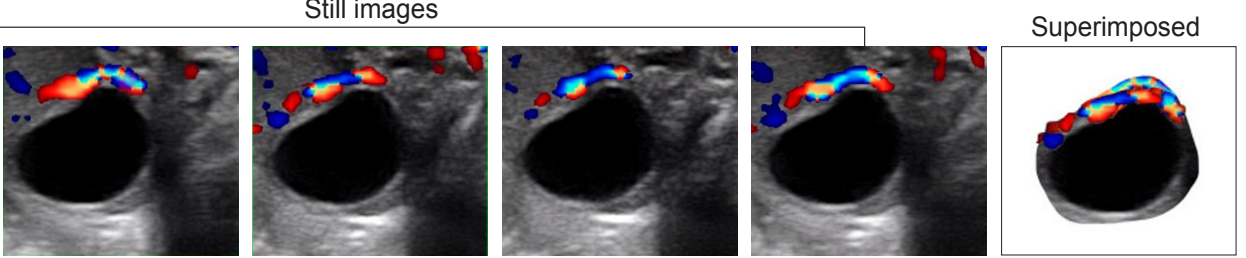

WUF

$38.9 \%$

\section{Cow 2}

Pixel area

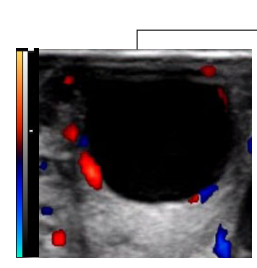

Still images
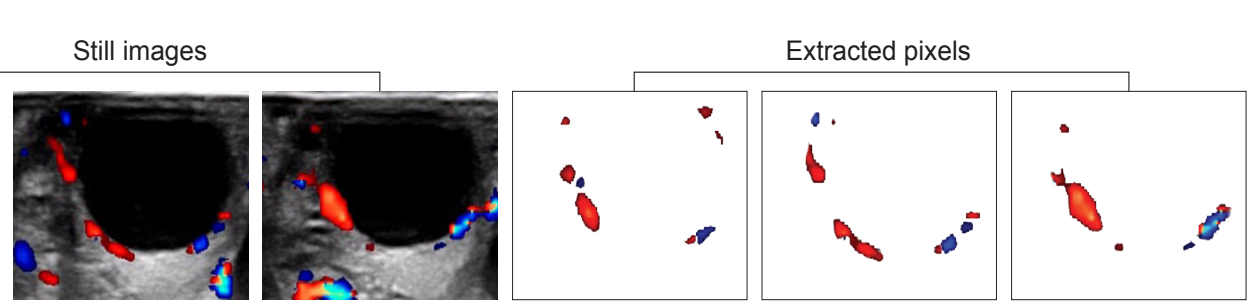

Mean

pixel

area

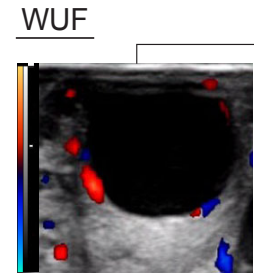

Still images
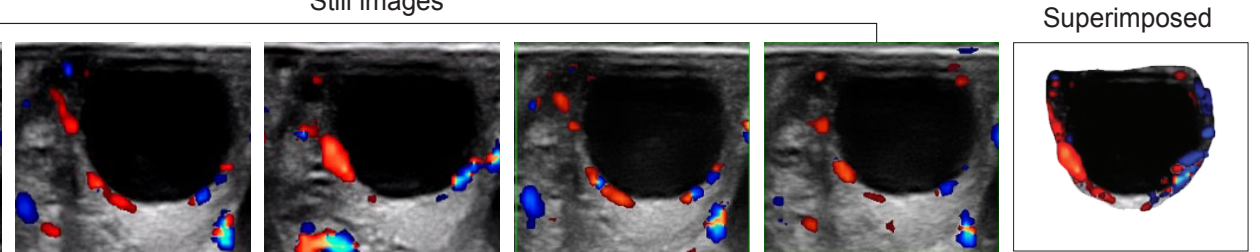

WUF

$61.2 \%$

Figure 1. Illustrations of evaluation of follicle blood flow using the area of colored pixels in the follicle wall and WUF methods in two cows. Mean pixel area resulting from the extracted colored Doppler signals from still images (pixel area method) and WUF obtained after superimposing five still images. Images were taken at maximum crosssectional diameter of the follicle at one specific time point.

\section{Subjective evaluation of follicle blood flow at the farm}

Follicle wall blood flow was estimated after a slow continuous motion of the ultrasound probe across the surface of the follicle, until the entire circumference of the follicle was displayed at least three times. The classification of the follicle wall blood flow was made by one trained operator, using vascular percentage ( 0 $100 \%)$ of the visual wall area filled with color signals (Ginther, 2007).

Subjective evaluation of follicle blood flow at the laboratory

The percentage of follicle wall blood flow was obtained in the laboratory using the video clips of the entire scan of the follicle by four operators who were unaware of the animal's ID, experimental time points of the videos, and results from the real-time scans (Ginther, 2007; Ginther et al., 2007a). The operators evaluated the videos in the laboratory at the same time, and videos were played as many times as they requested. Every video clip evaluation was timed and classified separately for each operator.

Objective evaluation of follicle blood flow to obtain the colored pixel area

Digital images were exported in DICOM and JPG format from the hard drive of the ultrasound 
machine to a computer. Three different images with maximum Doppler signals of blood flow from the same follicle and the same time points were processed for the quantification of the area with colored pixels. Colored areas or pixel aggregates were manually selected, extracted, and saved using Adobe Photoshop software as described for ultrasound images (Ginther and Utt, 2004; Ginther, 2007). Colored pixels were considered to be part of the follicle wall when found within $3 \mathrm{~mm}$ from the edge of the follicle wall. Image $J^{\circledR}$ software was used to measure the area of colored Doppler signals (Ginther and Utt, 2004; Ginther, 2007). The mean area $\left(\mathrm{mm}^{2}\right)$ of colored pixels in the follicle wall from three images in each time point was used for each animal (Fig. 1).

Objective evaluation of follicle blood flow to obtain the WUF

The previously selected images were also analyzed using Adobe Photoshop CS4 for the WUF end point. Initially, using the software, a sequence of $4-7$ still images from the same follicle, same time point, and same maximum circumference were overlapped to generate an image with the overall area of blood flow colored signs in the follicle wall (Fig. 1). Afterwards, the follicle wall circumference (WC) and the length of the follicle wall with colored signals (WS) were measured (Miura et al., 2014). Therefore, a formula was used to calculate the percentage of WUF for every follicle and time point as follows: $\mathrm{WUF}=\mathrm{WS} \div \mathrm{WC} \mathrm{x}$ 100.

\section{Statistical analyses}

Numerical data from all the subjective and objective evaluations of blood flow were converted and expressed as percentage change to allow proper comparisons among end points that had different units. Data were normalized to maximum diameter (hour 0 ) of the dominant follicle. Data were analyzed by Proc mixed-model (Statistical Analysis System, Version 9.2 for Windows; SAS Institute, Cary, NC, USA) to determine whether or not the data from each method had a group effect, hour effect, and interaction. This was performed to show that the data followed a similar trend in their slope, being essential for the validation of the methods. Pearson correlation coefficients $(r)$ were used to determine the effectiveness of the training by showing that the four operators had achieved a high degree of agreement in assigning blood flow estimates during subjective evaluations in the laboratory. Pearson correlation analyses were also used to compare the correlations between the subjective methods (data generated at the farm and in the laboratory - video clips) of evaluating follicle wall blood flow with the objective method, which used still images (pixel area and WUF). These correlation analyses were used to validate the reliability of the methods. In addition, Fisher's $r-z$ conversion tests were used to compare two different sets of correlations between subjective and objective methods of follicle blood flow evaluation. A probability of $\mathrm{P}<0.05$ indicated that a difference was significant.

\section{Results}

During a 7-day training period, operators analyzed 280 video clips. Results on the first day of training showed correlations between operators ranging from $r=0.44$ to $r=0.80$. Correlations between all pairs of operators started to become stronger from the second day onwards, with $r$ - values ranging from $r \geq 0.8$ to $r \geq$ 0.9 for 6 consecutive days (data not shown). Difference $(\mathrm{P}<0.0001)$ among operators was observed on day 1 ; however, no differences were observed from day 2 onwards until the end of the training (day 7). The progress and efficacy of the training could also be seen by the improvement in agreement of results among operators and closer slopes on day 7 compared to day 1 (Fig. 2).

After completion of training, follicle blood flow of 21 animals ( $n=238$ video clips) was analyzed subjectively in the laboratory by the four different operators for final data collection. No difference or interaction was observed among operators when follicle blood flow data was normalized to maximum diameter of the preovulatory follicle (Fig. 3A). Therefore, data from all operators were combined and a pooled average was used for further comparisons among different methods.

Comparison among subjective (barn vs. laboratory evaluation) and objective (colored pixel area and WUF) methods after data were transformed to percentage change showed an increase $(\mathrm{P}<0.0001)$ in follicle blood flow over time and a group-time interaction $(\mathrm{P}<0.0001)$, but no differences among the methods of evaluation. A comparison of raw data among the end points with similar units (barn data, laboratory data, and WUF) produced a similar time effect. Overall, follicle blood flow percentages assigned at the barn were greater $(\mathrm{P}<0.0001)$ than the values obtained from the laboratory and WUF method. However, the laboratory data did not differ $(\mathrm{P}>0.05)$ from the WUF data. Despite differences between barn data and WUF, all three methods showed similar relative changes over time, which was evident by the lack of interaction in the statistical analyses (Fig. 3B).

Pearson correlation coefficients among methods and operators showed that the different methods for evaluating follicle blood flow exhibited positive correlations $(r=0.42-0.96$; $\mathrm{P}<0.0001$; Table 1). Higher $(\mathrm{P}<0.001)$ correlations were obtained between WUF and laboratory evaluation than between WUF and pixel area and WUF and barn data. Furthermore, positive correlations $(r=0.61-0.96$; $\mathrm{P}<0.0001)$ were found between subjective methods of evaluation (barn vs. laboratory data), and operators. Fisher's $\mathrm{r}-\mathrm{z}$ tests detected that WUF had higher $(\mathrm{P}<0.0003)$ correlation coefficients than the pixel area when comparing those with barn $(r=0.70 \mathrm{vs}$. $r=0.42)$ and laboratory $(r=0.84 v s . r=0.62$; Table 2) data. Subjective evaluations at the laboratory versus the barn produced stronger correlations with pixel area $(\mathrm{P}<0.01)$ and WUF $(\mathrm{P}<0.0008)$. 


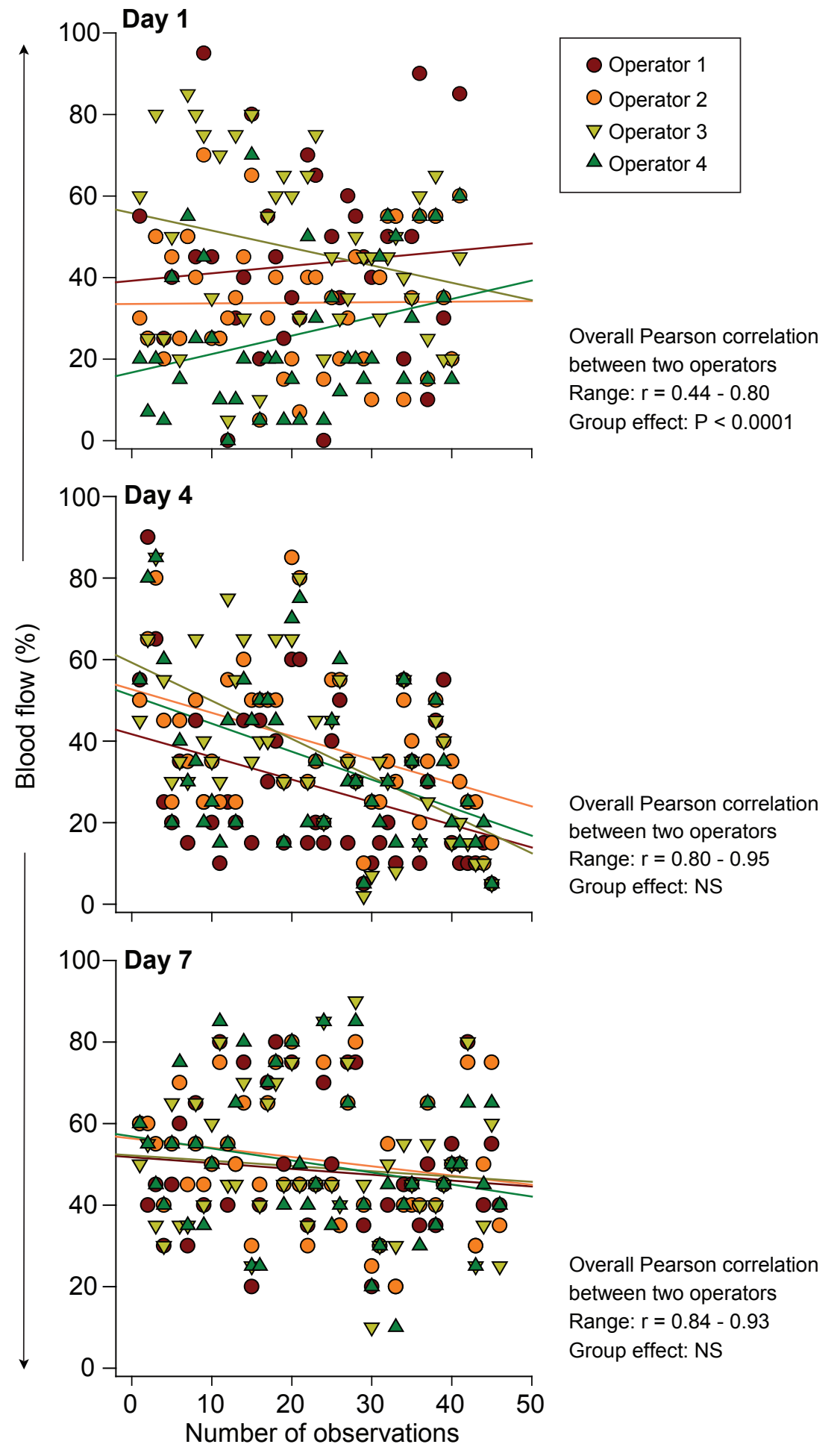

Figure 2. Scatter plots showing the dispersion of data among four operators on days 1 , 4, and 7 of the training period. Pearson correlation ranges are shown for the progress and efficacy of the training among operators. Group effects are indicated. NS = non-significant. 


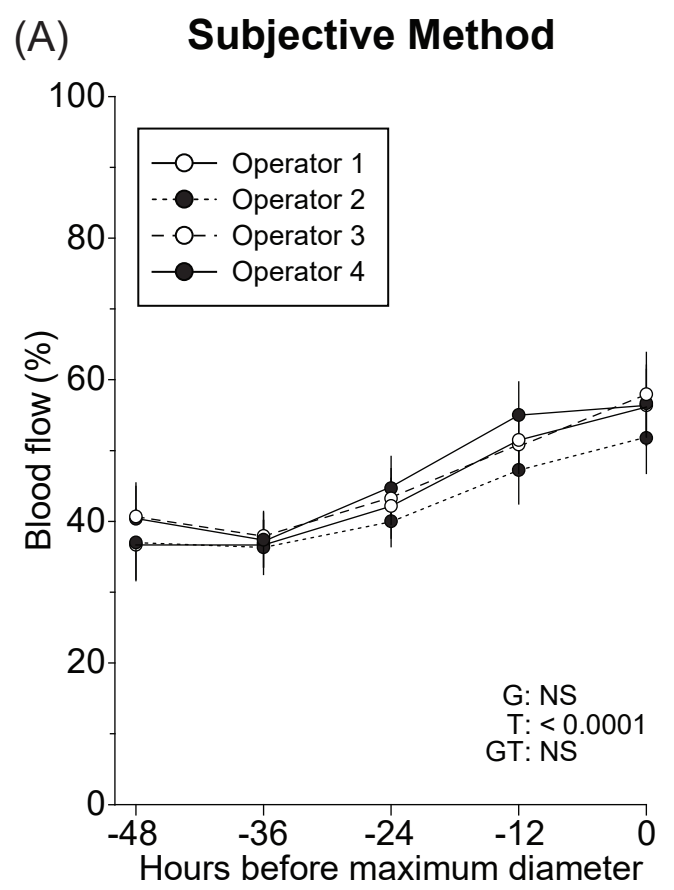

(B) Subjective and Objective Methods

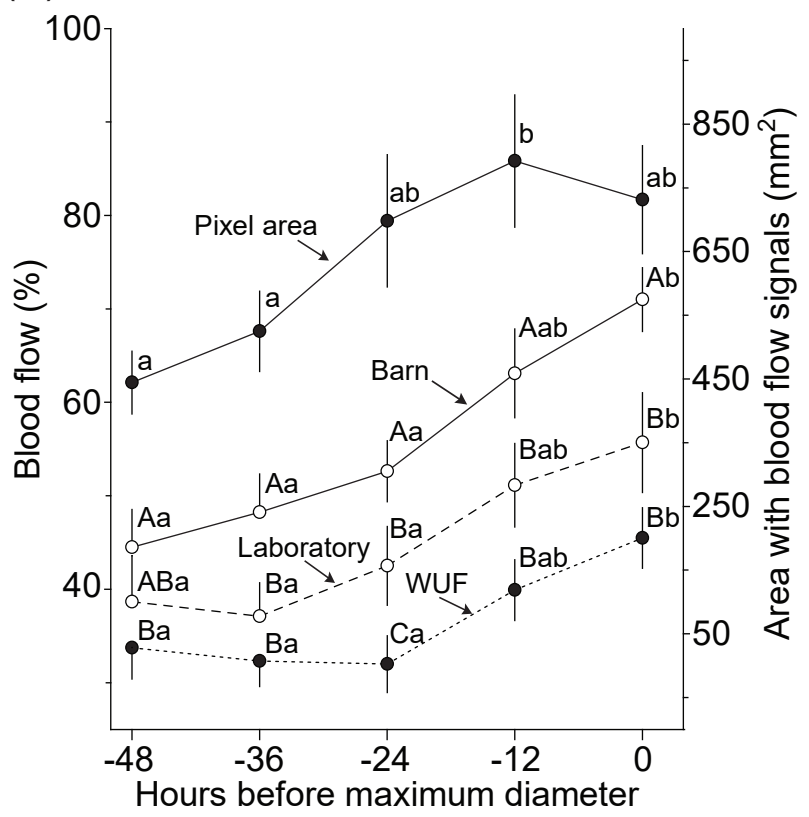

Figure 3. Comparisons (A) among operators using a subjective method, and (B) among different subjective and objective methods for evaluation of follicle blood flow. (B) Because of the different units ( $\mathrm{mm}^{2}$ and percentage) used for evaluation of follicle blood flow, the overall comparison among methods was done after data were transformed to percentage change of blood flow. ${ }^{a, b}$ Within each method, non-common superscripts differed $(\mathrm{P}<0.05)$. ${ }^{\mathrm{A}, \mathrm{B}}$ Within each hour, barn, laboratory, and WUF values with non-common superscripts differed $(\mathrm{P}<0.05)$. When comparing transformed data (pixel area, barn, laboratory, and WUF), no differences $(\mathrm{P}>0.05)$ within hours were observed, except for hour -48 where pixel area had greater $(\mathrm{P}<0.05)$ values than the other groups. Comparison of four groups (transformed data): G: NS, T: P $<0.0001$, GxT: P $<0.0001$. Comparison of three groups (raw data): G: P $<0.0001$, T: P $<0.0001$, GxT: NS. 
Table 1. Pearson correlation coefficient $(r)$ among operators, different subjective, and objective methods of evaluation of follicular wall blood flow.

\begin{tabular}{lccccccc}
\hline & & \multicolumn{5}{c}{ Laboratory evaluation* } \\
\cline { 3 - 7 } & Pixel area & Barn data & Operator 1 & Operator 2 & Operator 3 & Operator 4 & Mean \\
\hline WUF & $0.57^{\mathrm{a}}$ & $0.70^{\mathrm{b}}$ & 0.82 & 0.78 & 0.83 & 0.80 & $0.84^{\mathrm{A}, \mathrm{c}}$ \\
Pixel area & & 0.42 & 0.56 & 0.64 & 0.55 & 0.63 & $0.62^{\mathrm{B}, \mathrm{C}}$ \\
Barn data & & 0.61 & 0.61 & 0.64 & 0.62 & $0.66^{\mathrm{C}}$ \\
Operator 1 & & & 0.81 & 0.96 & 0.88 & 0.96 \\
Operator 2 & & & & 0.81 & 0.88 & 0.92 \\
Operator 3 & & & & & 0.88 & 0.96 \\
Operator 4 & & & & & & 0.96 \\
\hline
\end{tabular}

${ }_{\mathrm{a}, \mathrm{b}, \mathrm{c}} \mathrm{Within}$ a row, non-common superscripts differ $(\mathrm{P}<0.001)$.

${ }_{\mathrm{A}, \mathrm{B}, \mathrm{C}}$ Within a column, non-common superscripts differ $(\mathrm{P}<0.0003)$.

All correlations were highly significant $(\mathrm{P}<0.0001)$.

*Number of observations per end point ranged from 124 - 143.

Table 2. Fisher's $r-z$ conversion test comparing differences between correlation coefficients of subjective and objective methods of evaluation of follicle wall blood flow.

\begin{tabular}{lccc}
\hline & Pixel area & WUF & Fisher's r- z Conversion \\
\hline Barn data & $0.42^{\mathrm{a}}$ & $0.70^{\mathrm{a}}$ & $\mathrm{P}<0.0003$ \\
Laboratory data & $0.62^{\mathrm{b}}$ & $0.84^{\mathrm{b}}$ & $\mathrm{P}<0.0001$ \\
Operator 1 & 0.56 & 0.81 & $\mathrm{P}<0.0001$ \\
Operator 2 & 0.64 & 0.78 & $\mathrm{P}<0.01$ \\
Operator 3 & 0.55 & 0.82 & $\mathrm{P}<0.0001$ \\
Operator 4 & 0.63 & 0.80 & $\mathrm{P}<0.03$ \\
\hline
\end{tabular}

${ }^{\mathrm{a}, \mathrm{b}}$ Within columns, pixel area and WUF differed $(\mathrm{P}<0.01$ and $\mathrm{P}<0.0008$, respectively) between barn and laboratory data using the Fisher's r-z conversion test.

\section{Discussion}

This is the first report to compare different methodologies for evaluation of follicle wall blood flow, either subjectively or objectively in any species. A novel objective method (WUF) has been developed producing more efficient results when compared to the subjective method performed at the barn. The establishment of a reliable gold standard test for evaluation of follicle wall blood flow will provide support and guidance to the results produced subjectively by any operator. Furthermore, this new objective technique might help in the near future with the development of a follicle blood flow evaluation software for color Doppler machines, where more precise measurements would generate reliable data of follicle vascularity in the field.

In this study, a novel method (WUF) for objectively evaluating follicle blood flow was developed and compared with a previously reported method of measuring area of colored pixels in CLs (Acosta et al., 2002, 2003). The WUF method was tailored to objectively evaluate blood flow in different frames considering the percentage of the follicle wall with color signals at the largest circumference of the follicle. In the former studies (Silva et al., 2006; Ginther, 2007; Siddiqui et al., 2009a), follicle blood flow was assessed by gradually moving and aligning the ultrasound probe over the surface of the follicle. When the overall color flow signals were displayed, estimated blood flow percentage scores were assigned subjectively by the operator's judgment. Although the subjective method for evaluation of follicle blood flow has been extensively used over a long period of time in women and domestic animals (Bourne et al., 1991; Brannstorm et al., 1998; Miyazaki et al., 1998; Gastal et al., 2006; Silva et al., 2006; Siddiqui et al., 2009a, b), its validity has not been sufficiently established. The accuracy between the subjective and objective methodologies to evaluate follicle wall blood flow has been deduced from reports that evaluated CL blood flow in heifers and mares (Ginther and Utt, 2004; Ginther et al., 2007a; Araujo and Ginther, 2009).

In this study, when evaluating follicle blood flow, a similar parallelism between data of the subjective and objective evaluation methods was observed as previously reported for evaluation of CL but not follicle blood flow in mares (Ginther et al., 2007a). However, inadequateness regarding the reliability of those methods could be claimed because the approaches used for evaluating blood flow were different between both methods, i.e. continuous motion evaluation (Bhal et al., 1999; Gastal et al., 2006; Ginther, 2007) versus still image evaluation (Miyazaki et al., 1998; Ginther, 2007). Furthermore, the use of an objective pixel analysis method as a gold standard test to correlate findings with percentage or scoring evaluation in subjective methods could be questionable mainly for evaluations of blood flow in the follicle wall, considering the distinct geometry and morphological characteristics (Ali et al., 2001) of the POF versus the CL. Anatomical and ultrasonographic characteristics of 
follicles and CLs are consistently different. Follicles are hollow spherical structures, and CLs are mostly a solid mass of luteinized cells with the presence or not of a central hollow cavity (Gaytán et al., 1999; Hunter, 2003). The pixel analysis method may be suitable for validation of subjective methods for CL blood flow estimation where the morphology of the structure allows the pixel analysis in a large surface area and not in a restricted area like the follicle wall. Therefore, it is clear that the validation of a subjective method for evaluation of follicle blood flow cannot be deduced from an objective method of blood flow evaluation of CLs, even though high correlations between methods and operators have been previously reported (Ginther et al., 2007c). Thus, it is also possible that a similar methodology to objectively evaluate blood flow for both structures (follicle and CL) could be inaccurate. Therefore, to overcome the potential flaws in previous methodologies and have a more accurate evaluation method, the WUF approach was developed to evaluate follicle wall blood flow.

Correlations among different methods showed WUF as a more reliable methodology to evaluate follicle blood flow, compared with the method of measuring area of colored pixels. When comparing raw data, the follicle blood flow assigned at the barn was greater than the WUF values; however, WUF data displayed a similar trend compared with the subjective barn and laboratory evaluations during the $24 \mathrm{~h}$ before ovulation. Taken together, these results supported our central hypothesis that WUF is an accurate and reliable objective method to evaluate follicle blood flow.

Comparisons between subjective evaluations (barn and laboratory) versus the objective evaluations (pixel area and WUF) showed superior results (strong correlations) when data were evaluated in the laboratory. In a previous study (Araujo and Ginther, 2009) on validation of the subjective method for evaluation of CL blood flow in heifers, compared with an objective method, no differences were found between data collected at the barn or in the laboratory for both methods. However, from our study it is evident that the subjective evaluation performed in the laboratory was a more reliable methodology than at the barn. This disparity could be due to the fact that at the barn the operator is more distracted due to multitasking, data collection, and concerns with animal welfare. Furthermore, the operators at the laboratory had more time to evaluate follicle blood flow without any distractions and they could review the video clips several times, which was not possible for the evaluations performed at the barn. In addition, although the operator was trained before the barn data collection, the training status of the operator was not evaluated. Another factor that might have been responsible in part for these results is the unconscious bias that might develop in the mind of an operator while estimating follicle blood flow in consecutive exams at the barn, since the operator may have access to the data from previous time points.

Training sessions allowed improvement of accordance in results between pairs of operators, with significant increase in $r$ values between the first and the subsequent sessions. Afterwards, high correlations $(\geq 0.8)$ were observed between pairs of operators. During the training sessions, operators were allowed to review correlation results between each other from previous sessions before the beginning of the evaluation of the videos in a new session. This approach allowed discussion and reevaluation of video clips in specific time points, which generated knowledge and improved the accordance of results among operators after $3-4$ days of training.

In conclusion, WUF was an accurate and reliable method to objectively evaluate follicle wall blood flow in cows. According to the correlation analyses, the method of measuring the area of colored pixels in the follicle wall did not strongly support the validation of subjective methods for follicle blood flow evaluations. Subjective estimations of follicle blood flow at the laboratory produced more accurate results compared to the evaluations performed at the barn. Moreover, operator training for a short period of time was important before a subjective method for evaluation of follicle blood flow could be used efficiently by different individuals. Finally, the establishment of the WUF technique may stimulate the designing of a software for color Doppler machines to be used in realtime scanning for objective characterization of follicle blood flow. Generation of objective and automatized data will allow precise evaluations of the impact of follicle wall blood flow on subsequent reproductive outcomes.

\section{Conflict of interest}

The authors declare that there is no conflict of interest that could be perceived as prejudicing the impartiality of the research reported.

\section{Funding}

This work was supported by Southern Illinois University, Carbondale, IL. S.G.S de Tarso was the recipient of a $\mathrm{PhD}$ scholarship from the National Council for Scientific and Technological Development (CNPq), Brazil.

\section{References}

Acosta TJ, Yoshizawa N, Ohtani M, Miyamoto A. 2002. Local changes in blood flow within the early and midcycle corpus luteum after prostaglandin $\mathrm{F}(2$ alpha) injection in the cow. Biol Reprod, 66:651-658.

Acosta TJ, Hayashi KG, Ohtani M, Miyamoto A. 2003. Local changes in blood flow within the preovulatory follicle wall and early corpus luteum in cows. Reproduction, 125:759-767.

Acosta TJ, Miyamoto A. 2004. Vascular control of ovarian function: ovulation, corpus luteum formation and regression. Anim Reprod Sci, 82-83:127-140.

Acosta TJ. 2007. Studies of follicular vascularity associated with follicle selection and ovulation in cattle. J Reprod Dev, 53:39-44.

Adams GP, Jaiswal R, Singh J, Malhi P. 2008. 
Progress in understanding ovarian follicular dynamics in cattle. Theriogenology, 69:72-80.

Ali A, Lange A, Gilles M, Glatzel PS. 2001. Morphological and functional characteristics of the dominant follicle and corpus luteum in cattle and their influence on ovarian function. Theriogenology, 56:569576.

Araujo RR, Ginther OJ. 2009. Vascular perfusion of reproductive organs in pony mares and heifers during sedation with detomidine or xylazine. Am J Vet Res, 70:141-148.

Bhal PS, Pugh ND, Chui DK, Gregory L, Walker SM, Shaw RW. 1999. The use of transvaginal power Doppler ultrasonography to evaluate the relationship between perifollicular vascularity and outcome in invitro fertilization treatment cycles. Hum Reprod, 14:939-945.

Blasco L, Wu C, Flickinger GGL, Pearlmutter DC, Mikhail G. 1975. Cardiac output and genital blood flow distribution during the preovulatory period in rabbits. Biol Reprod, 13:581-586.

Bollwein H, Meyer HHD, Maierl J, Weber F, Baumgartner U, Stolla R. 2000. Transrectal doppler sonography of the uterine blood flow in cows during the estrous cycle. Theriogenology, 53:1541-1552.

Bollwein H, Baumgartner U, Stolla R. 2002 Transrectal Doppler sonography of uterine blood flow in cows during pregnancy. Theriogenology, 57:2053-2061.

Bollwein H, Lüttgenau J, Herzog K. 2012. Bovine luteal blood flow: basic mechanism and clinical relevance. Reprod Fertil Dev, 25:71-79.

Bourne TH, Jurkovic D, Waterstone J, Campbell S, Collins P. 1991. Intrafollicular blood flow during human ovulation. Ultrasound Obstet Gynecol, 1:53-59.

Brannstorm M, Zackrisson U, Josefsson B, Granberg S, Collins WP, Bourne T. 1998 Preovulatory changes of blood flow in different regions of the human follicle. Fertil Steril, 69:435-442.

Coulam CB, Goodman C, Rinehart JS. 1999. Colour Doppler indices of follicular blood flow as predictors of pregnancy after in-vitro fertilization and embryo transfer. Hum Reprod, 14:1979-1982.

de Tarso SGS, Gastal GDA, Bashir ST, Gastal MO, Apgar GA, Gastal EL. 2015. Follicle vascularity coordinates corpus luteum blood flow and progesterone production. Reprod Fertil Dev. doi: 10.1071/RD15223

Dickey R. 1997. Doppler ultrasound investigation of uterine and ovarian blood flow in infertility and early pregnancy. Hum Reprod Update, 3:467-503.

Eversole DE, Browne MF, Hall JB, Dietz RE. 2009. Body condition scoring beef cows. (Publications and Educational Resources, Virginia Tech Blacksburg, VA.) Available on: https//pubs. ext.vt.edu/400/400-795/400795.html.

Fein M, Delorme S, Weisser G, Zuna I, van Kaick G. 1995. Quantification of color Doppler for the evaluation of tissue vascularization. Ultrasound Med Biol, 21:1013-1019.

Gastal EL, Gastal MO, Ginther OJ. 2006 Relationships of changes in B-mode echotexture and colour-Doppler signals in the wall of the preovulatory follicle to changes in systemic oestradiol concentrations and the effects of human chorionic gonadotrophin in mares. Reproduction, 131:699-709.

Gastal EL, Gastal MO. 2011. Equine preovulatory follicle: blood flow changes, prediction of ovulation and fertility. Rev Bras Reprod Anim, 35:239-252.

Gaytán F, Morales C, Garcia-Pardo L, Reymundo C, Bellido C, Sánchez-Criado JE. 1999. A quantitative study of changes in the human corpus luteum microvasculature during the menstrual cycle. Biol Reprod, 60:914-919.

Ginther OJ. 1998. Ultrasonic Imaging and Animal Reproduction: Book 3, Cattle. Cross Plains, WI: Equiservices Publishing.

Ginther OJ, Utt MD. 2004. Doppler ultrasound in equine reproduction: principles, techniques, and potential. J Equine Vet Sci, 24:516-526.

Ginther OJ. 2007. Ultrasonic Imaging and Animal Reproduction: Book 4, Color-Doppler Ultrasonography. Cross Plains, WI: Equiservices Publishing.

Ginther OJ, Gastal EL, Gastal MO, Beg MA. 2007a. Effect of prostaglandin F2alpha on ovarian, adrenal, and pituitary hormones and on luteal blood flow in mares. Domest Anim Endocrinol, 32:315-328.

Ginther OJ, Gastal EL, Gastal MO, Siddiqui MAR, Beg MA. 2007b. Relationships of follicle versus oocyte maturity to ultrasound morphology, blood flow, and hormone concentrations of the preovulatory follicle in mares. Biol Reprod, 77:202-208.

Ginther OJ, Gastal EL, Gastal MO, Utt MD, Beg MA. 2007c. Luteal blood flow and progesterone production in mares. Anim Reprod Sci, 99:213-220.

Herzog K, Bollwein H. 2007. Application of Doppler ultrasonography in cattle reproduction. Reprod Domest Anim, 42:51-58

Huey S, Abuhamad A, Barroso G, Hsu MI, Kolm P, Mayer J, Oehninger S. 1999. Perifollicular blood flow Doppler indices, but not follicular pO2, pCO2, or $\mathrm{pH}$, predict oocyte developmental competence in in vitro fertilization. Fertil Steril, 72:707-712.

Hunter RHF. 2003. Physiology of the Graafian Follicle and Ovulation. New York, NY: Cambridge University Press.

Miura R, Haneda S, Lee H-H, Miyamoto A, Shimizu T, Miyahara K, Miyake Y-I, Matsui M. 2014. Evidence that the dominant follicle of the first wave is more active than that of the second wave in terms of its growth rate, blood flow supply and steroidogenic capacity in cows. Anim Reprod Sci, 145:114-122.

Miyamoto A, Shirasuna K, Sasahara K. 2009. Local regulation of corpus luteum development and regression in the cow: impact of angiogenic and vasoactive factors. Domest Anim Endocrinol, 37:159-169.

Miyazaki T, Tanaka M, Miyakoshi K, Minegishi K, Kasai K, Yoshimura Y. 1998. Power and colour Doppler ultrasonography for the evaluation of the vasculature of the human corpus luteum. Hum Reprod, 13:2836-2841.

Shrestha SM, Costello MF, Sjoblom P, McNally G, Bennett M, Steigrad SJ, Hughes GJ. 2006. Power doppler ultrasound assessment of follicular vascularity in the early follicular phase and its relationship with outcome of in vitro fertilization. J Assist Reprod Genet, 23:161-169. 
Siddiqui MAR, Almamun M, Ginther OJ. 2009a. Blood flow in the wall of the preovulatory follicle and its relationship to pregnancy establishment in heifers. Anim Reprod Sci, 113:287-292.

Siddiqui MAR, Gastal EL, Gastal MO, Almamun M, Beg MA, Ginther OJ. 2009b. Relationship of vascular perfusion of the wall of the preovulatory follicle to in vitro fertilisation and embryo development in heifers. Reproduction, 137:689-697.

Siddiqui MAR, Ferreira JC, Gastal EL, Beg MA, Cooper DA, Ginther OJ. 2010. Temporal relationships of the LH surge and ovulation to echotexture and power Doppler signals of blood flow in the wall of the preovulatory follicle in heifers. Reprod Fertil Dev, 22:1110-1117.

Silva LA, Gastal EL, Gastal MO, Beg MA, Ginther OJ. 2006. Relationship between vascularity of the preovulatory follicle and establishment of pregnancy in mares. Anim Reprod, 3:339-346.

Viana JHM, Arashiro EKN, Siqueira LGB, Ghetti AM, Areas VS, Guimarães CRB. 2013. Doppler ultrasonography as a tool for ovarian management. Anim Reprod, 10:215-222.

York G, Kim Y. 1999. Ultrasound processing and computing: review and future directions. Annu Rev Biomed Eng, 1:559-588. 